\title{
Plenary presentations and public citations from The American Association for Thoracic Surgery
}

\author{
Mohamed Kamel, MD, ${ }^{\mathrm{a}}$ Yusuke Terasaki, MD, ${ }^{\mathrm{b}}$ Prasad S. Adusumilli, MD, FACS, ${ }^{\mathrm{c}}$ and
} Brendon M. Stiles, MD

\section{ABSTRACT}

Objective: We examined the impact of work presented in the plenary sessions at the meeting of The American Association for Thoracic Surgery (AATS), by determining how frequently the published papers corresponding to the session presentations during the past 20 years, were cited; those that were most cited were identified.

Methods: We reviewed the AATS meeting programs from the 20-year period from 1994 to 2014 and identified the corresponding publications in the Journal of Thoracic and Cardiovascular Surgery (JTCVS) from all abstracts presented at the plenary sessions. Papers were categorized as cardiac, thoracic, or congenital. References were evaluated for subsequent citation in the Web of Science (WoS), and Google Scholar (GS). We determined both the median number of citations overall, and per year. For comparison, we evaluated numbers of citations in WoS from current JTCVS papers in issues containing the 3 most-cited plenary session papers.

Results: Among 195 published plenary papers, the median number of citations in WoS and GS was 49 and 76, respectively. The median total number of citations in WoS was as follows: 51 for cardiac-category papers $(\mathrm{n}=105)$; 61 for thoracic $(\mathrm{n}=55)$, and 41 for congenital $(\mathrm{n}=35)$. These values were higher than the median total number of citations for contemporary nonplenary JTCVS papers: cardiac $(22, \mathrm{n}=55 ; P<.001)$; thoracic $(31.5, \mathrm{n}=8 ; P=.183)$; and congenital $(15.5, \mathrm{n}=24 ; P=.002)$ papers published in JTCVS. The median number of citations per year since publication for plenary publications was 5.9 (cardiac), 6 (thoracic), and 3.7 (congenital), respectively.

Conclusions: Publications corresponding to the plenary sessions of the AATS are highly cited and include some of the seminal studies in our field in the past 20 years. (J Thorac Cardiovasc Surg 2016;151:30-4)

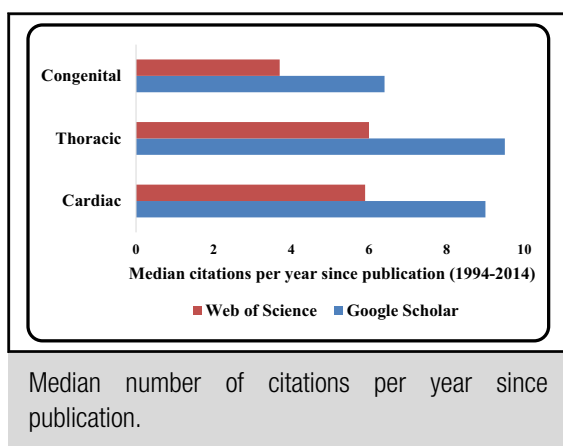

\section{Central Message}

Publications from the plenary sessions of the AATS meeting are highly cited and include some of the seminal studies in the field of thoracic surgery.

\section{Perspective}

The plenary scientific session of the AATS meeting provides a forum for presentation and discussion of the most-significant clinical research in the field of cardiothoracic surgery. Publications corresponding to the presentations are highly cited and include some of the seminal studies in the field in the past 20 years.

See Editorial Commentary page 35 .

See Editorial page 23.
In his opening remarks at the inaugural meeting of The American Association for Thoracic Surgery (AATS), on June 10th, 1918, S.J. Meltzer, the first president, eloquently described to a group of general surgeons the reason for the society's creation: for the advancement of the knowledge of

From the ${ }^{\mathrm{a} D e p a r t m e n t}$ of Cardiothoracic Surgery and ${ }^{\mathrm{b}}$ Department of General Surgery, NewYork-Presbyterian Hospital/Weill Cornell Medical Center; and ${ }^{\mathrm{c}}$ Thoracic Service, Memorial Sloan Kettering Cancer Center, New York, NY.

Read at the 95th Annual Meeting of The American Association for Thoracic Surgery, Seattle, Washington, April 25-29, 2015.

M.K. and Y.T. contributed equally to this work.

Received for publication April 28, 2015; revisions received Aug 17, 2015; accepted for publication Aug 26, 2015; available ahead of print Sept 25, 2015.

Address for reprints: Brendon M. Stiles, MD, 525 E 68th St, \#Mb 110, New York, NY 10065 (E-mail: brs9035@med.cornell.edu).

$0022-5223 / \$ 36.00$

Copyright (c) 2016 by The American Association for Thoracic Surgery

http://dx.doi.org/10.1016/j.jtcvs.2015.08.103 and skill in thoracic surgery. ${ }^{1} \mathrm{He}$ emphasized the need to "single out" the thoracic cavity, and to focus on pathologies that occur above the diaphragm. Until that time, the chest had garnered little attention from most of the leading surgeons and experimental investigators.

Now, close to a century later, the field of thoracic surgery is robust, thanks to the tireless work of many pioneering surgeons and institutions. The field has branched out into the subspecialties of cardiac, general thoracic, and congenital surgery. Fueled by surgical and technologic advances, research in the field of thoracic surgery has grown exponentially. Each year, from among hundreds of abstracts, the AATS abstract committee selects those they believe to describe the most important and influential clinical research in each subspecialty, to be presented at the plenary scientific session. The aim of this study is to examine the impact of the work selected by the AATS for 


\section{Abbreviations and Acronyms \\ AATS $=$ The American Association for Thoracic Surgery \\ GS $=$ Google Scholar \\ JTCVS $=$ The Journal of Thoracic and \\ Cardiovascular Surgery \\ $\mathrm{WoS}=$ Web of Science citation index}

this session, by determining how frequently the published papers from the session were cited. We sought to identify and capture the historical significance of the most-cited publications of the past 20 years within the fields of cardiac, general thoracic, and congenital surgery.

\section{METHODS}

We reviewed the AATS annual meeting programs from 1994 to 2014, using the AATS Web site to identify presentations from the Monday and Tuesday morning plenary sessions. The corresponding publications in The Journal of Thoracic and Cardiovascular Surgery (JTCVS) were identified using a PubMed search for a similar title with the same principal investigator, published within 2 years of the presentation. Papers were classified as cardiac, general thoracic, or congenital; the country and institution where the principal investigation took place were noted. Studies that were conducted across institutions were categorized as multi-institutional, and those conducted across institutions in different countries, international.

Our search of the identified papers was conducted in August 2015 using 2 databases; the Web of Science citation index (WoS; formerly ISI Web of Knowledge), and Google Scholar (GS). Web of Science includes data from 23,000 scientific journals from the year 1900 to the present. The WoS Web site is maintained by Thomson Reuters, which assigns a yearly impact factor to scientific journals. Google Scholar covers a wider array of scientific literature, including books and abstracts, and pre-prints and online reports not found in WoS.

For each discipline, the publications were arranged in descending order by number of citations determined by the WoS. A citation density (the number of times a work was cited per year since publication) was calculated for each publication. The median number of citations overall, and per year, was then calculated for each discipline. For comparison, we evaluated citation numbers in WoS from contemporary JTCVS papers published in issues containing the 3 most-cited plenary session papers in each subspecialty.

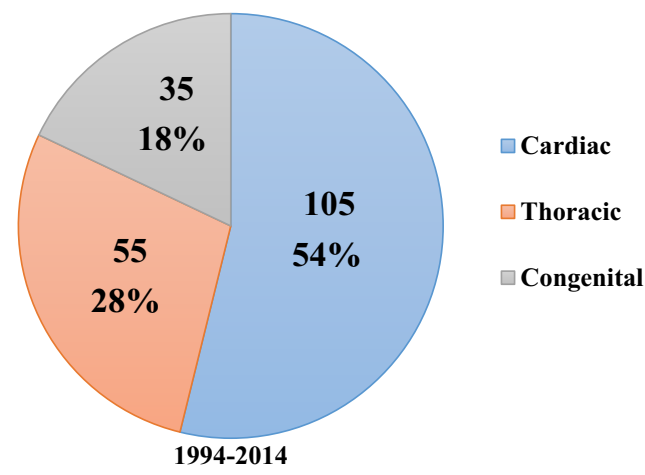

FIGURE 1. Numbers and percentages of AATS plenary papers (1994-2014), by subspecialty.

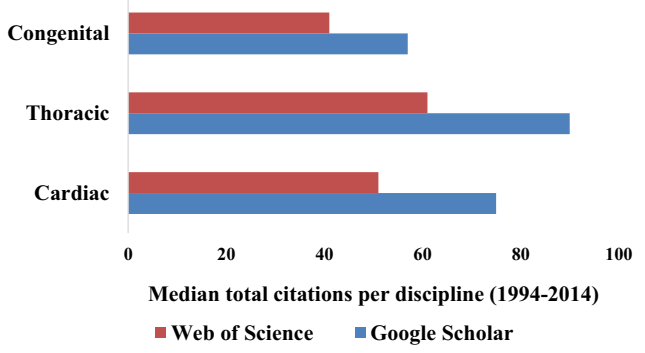

FIGURE 2. Median total citations of AATS plenary papers, per subspecialty.

\section{RESULTS}

\section{Total Citations and Citations per Year}

In the study period, 220 papers were presented at the Monday and Tuesday plenary sessions. Of these, 195 $(89 \%)$ were subsequently published in JTCVS, including 105 in the cardiac category, 55 in general thoracic, and 35 in congenital. Six were published in other journals (Figure 1). The median number of citations for the 3 disciplines combined was 49 in WoS, and 76 in GS. We divided the papers by subspecialty to determine, for each database, their total number of citations, and number of citations per year, since publication (Figures 2 and 3).

For papers in the cardiac category, the median total number of citations was 51 in WoS, and 75 in GS; the median number of citations per year was 5.9. For the general thoracic category, the median total number of citations was 61 in WoS, and 90 in GS; the median number of citations per year was 6 . For the congenital category, the median total number of citations was 41 in WoS, and 57 in GS; the median number of citations per year was 3.7.

For comparison, we evaluated total number of citations in WoS per year, from all of the papers published in JTCVS in the same issues as the 3 most-cited papers from each subspecialty: 55 cardiac, 24 congenital, and 8 general thoracic. The median total number of citations from JTCVS plenary session papers was significantly higher than the median total number of citations for contemporary nonplenary papers in each category: cardiac $(22, \mathrm{n}=55$; $P<.001)$; thoracic $(31.5, \mathrm{n}=8 ; P=.183)$; and congenital $(15.5, \mathrm{n}=24 ; P=.002)$ (Figure 4$)$.

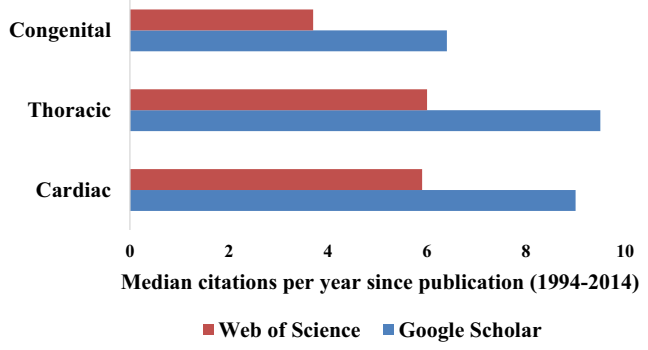

FIGURE 3. Median citations of AATS plenary papers, per year since publication. 


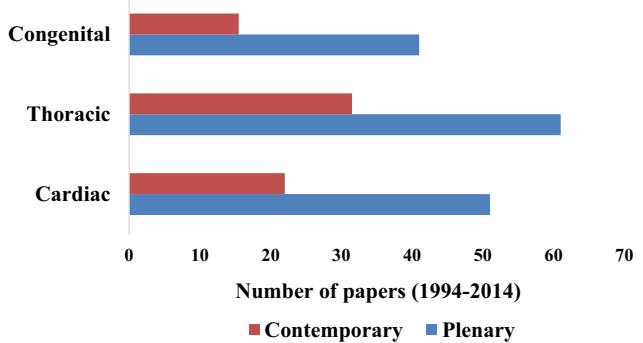

FIGURE 4. Numbers of AATS plenary papers, compared with contemporary papers.

\section{Most-Cited Papers in Each Subspecialty}

We chose to focus on citation number in WoS for the remainder of the study, to determine the most-cited papers in each subspecialty. Among papers in the cardiac category, the 5 most cited include papers on bilateral internal mammary grafting, off-pump coronary bypass, endovascular grafts for thoracic aortic aneurysms, management of ischemic mitral regurgitation, and valve preservation in ascending aorta repair (Table 1). Among papers in the thoracic category, the topics of the 5 most cited include lung metastasectomy, pleural mesothelioma, postintubation tracheal stenosis, primary lung tumors, and methods of postesophagectomy cervical anastomosis (Table 2). For papers in the congenital category, the most cited include papers on hemodilution and hypothermic cardiopulmonary bypass, arterial switch operation for transposition of the great arteries, brain maturation in patients with congenital heart defects, predictors of outcome after the Fontan procedure, and repair of congenital heart defects in lowweight newborns (Table 3).

Of the 94 papers published from 2005 to date, $9(9.6 \%)$ were labeled as highly cited papers by WoS (highly cited was defined as being in the top $1 \%$ of cited papers in the field for papers published in the past 10 years, along with papers from the past 2 years that received a very high number of citations in the current 2-month period). Of these, 5 papers were in the thoracic category, and 4 in the cardiac category.

\section{Country of Origin and Institutions}

An examination of the number of plenary papers, based on country of origin, showed that most came from the
United States, followed by Canada. More than 50 institutions were represented, spanning 11 countries. The institution with the most papers was the University of Toronto, at 12; Washington University and Cleveland Clinic were next, with 10 each (Table 4).

\section{DISCUSSION}

Since the inception of the AATS in 1918, the field of thoracic surgery has grown and evolved to an extent that S.J. Meltzer and his colleagues would never have imagined almost a century ago. In the same opening statement in which he described the outlook for the field of thoracic surgery, he listed some of the seminal work being conducted at the time: management of empyema by entering the pleural cavity, the concept of "intratracheal intubation" during surgery, and the rather controversial use of thoracotomy to manage pulmonary tuberculosis. ${ }^{1}$ Conspicuously absent from this list were any operations performed on the heart, as it would take another 3 decades before the likes of C. Walton Lillehei and F. John Lewis would perform the first open surgery on the heart.

The founders of the AATS surely would never have imagined that over the next century, the overwhelming majority of plenary research would be focused on the heart. The increased interest in cardiac surgery within the field is reflected by the number of citations within the top 5 papers: The total number of citation of the top paper in cardiac surgery is one and one half times that for the top paper in thoracic surgery. Although the focus on pathologies within thoracic surgery may have shifted, the same effort to investigate the most-controversial concepts in thoracic surgery can be seen in the plenary papers chosen by the AATS today. Novel approaches to performing procedures, technologic advances, new discoveries on perioperative care of cardiothoracic patients, and management of surgical complications are some of the overriding themes of the most-cited papers in our analysis.

Within adult cardiac surgery, and of all the papers we analyzed in our study, the most frequently cited was by Lytle and colleagues. ${ }^{2}$ They retrospectively compared outcomes for patients undergoing elective surgery for coronary artery bypass grafts who received either single or bilateral internal thoracic artery (ITA) grafts. Although

TABLE 1. Most-cited cardiac papers

\begin{tabular}{lllll}
\hline Year & \multicolumn{1}{c}{ Institution } & $\begin{array}{c}\text { First author and } \\
\text { reference number }\end{array}$ & \multicolumn{1}{c}{ Subject of the paper } & \multicolumn{1}{c}{ Citations (WoS) } \\
\hline 1999 & Cleveland Clinic & Lytle $^{2}$ & Bilateral internal mammary grafting & 474 \\
2003 & Emory University & Puskas $^{3}$ & Off-pump coronary bypass & 335 \\
1998 & Stanford University & Dake $^{4}$ & First-generation endovascular grafts for descending thoracic aorta & 318 \\
2001 & Cleveland Clinic & Gillinov $^{5}$ & Repair vs replacement of ischemic mitral valve & 305 \\
1998 & National Heart and Lung & Yacoub $^{6}$ & Valve preservation in ascending aorta repair & \\
& Institute, London & & & \\
\hline
\end{tabular}

WoS, Web of Science citation index. 
TABLE 2. Most-cited thoracic papers

\begin{tabular}{|c|c|c|c|c|}
\hline Year & Institution & $\begin{array}{l}\text { First author and } \\
\text { reference number }\end{array}$ & Subject of the paper & Citations (WoS) \\
\hline 1997 & Multi-institutional & Pastorino $^{7}$ & Long-term results of lung metastasectomy & 346 \\
\hline 2008 & Multi-institutional & Flores $^{8}$ & $\begin{array}{l}\text { Pneumonectomy vs pleurectomy for malignant } \\
\text { pleural mesothelioma }\end{array}$ & 198 \\
\hline 1995 & Massachusetts General Hospital, Boston, Mass & Grillo $^{9}$ & Postintubation tracheal stenosis & 196 \\
\hline 2008 & Multi-institutional & Boffa $^{10}$ & Surgical management of primary lung tumors & 195 \\
\hline 2000 & University of Michigan, Ann Arbor, Mich & Orringer $^{11}$ & Methods of cervical anastomosis & 172 \\
\hline
\end{tabular}

WoS, Web of Science citation index.

controversy remains about increased levels of wound infections in diabetic patients, this paper is significant in that it revealed that use of bilateral ITA grafting decreased the risks of death, reoperation, and percutaneous transluminal coronary angioplasties, compared with use of single ITA grafting. The topics discussed in the remaining papers that have the most citations are equally controversial, including off-pump coronary artery bypass grafting, and use of stent grafts for patients with descending thoracic aortic aneurysms.

The most-cited article in the field of thoracic surgery is the paper by Pastorino and colleagues, ${ }^{7}$ who highlighted the potentially curative value of lung metastatectomy of various malignancies. Finally, within the field of congenital cardiac surgery, the article by Jonas and colleagues ${ }^{12}$ had the most citations. They reported on a randomized controlled study that suggests the possibility of adverse neurologic and developmental outcomes for pediatric patients who undergo cardiac surgery with cardiopulmonary bypass using hemodilution protocols. Their article had almost twice as many citations as the second-most highly cited publication within the field of congenital surgery, owing to its broad-reaching contribution to the entire field of cardiac surgery. Their study was not only the first randomized controlled study within the congenital field, but also the first to look at hemodilution during cardiopulmonary bypass in adults and children.

Plenary session papers at the AATS meeting represent the most-relevant and highest-quality research presented at the annual meetings. Therefore, the current paper may be used as a concise resource of highly influential articles within the field of thoracic surgery, in its subcategories of adult cardiac, thoracic, and congenital cardiac surgery. The determination of the 5 most-cited papers within each field is corroborated by the use of 2 search engines, each catering specifically to members of the scientific community. Although we chose to use WoS to determine the top 5 rankings within each field, the same 5 papers would have been identified had we used GS instead.

Our study does have limitations. Unlike some bibliometric studies that have analyzed the most-cited papers within an entire field, we chose to focus on plenary presentations presented only at the AATS meeting and published only in JTCVS. As a result, other influential papers that were published in other journals are not captured in our study.

In addition, our study looked at papers published during the last 20 years only. An analysis of papers published during the entire course of AATS history (since 1918) may have allowed us to better visualize trends, for example, within each subspecialty per decade. O'Sullivan and colleagues ${ }^{17}$ did such an analysis of the 100 most-cited papers in the field of cardiac surgery; Ahmad and colleagues $^{18}$ did the same in their analysis of the 100 most-cited papers in the field of bariatric surgery.

In creating our table of the 5 most-cited papers within each subspecialty, we ranked each paper according to the absolute number of citations, instead of citation per year, thereby introducing bias toward older papers. This trend is mirrored in our findings-most of the papers were published more than a decade ago. An example of this bias is the exclusion of landmark papers, such as the study by Kirklin and colleagues ${ }^{19}$ of mechanical circulatory devices as an alternative to heart transplantation, which would have been in the top 5 had we used citations per year since publication.

TABLE 3. Most-cited congenital papers

\begin{tabular}{|c|c|c|c|c|}
\hline$\underline{\text { Year }}$ & Institution & $\begin{array}{l}\text { First author and } \\
\text { reference number }\end{array}$ & Subject of the paper & $\begin{array}{c}\text { Citations } \\
(\text { WoS }) \\
\end{array}$ \\
\hline 2003 & Boston Children's Hospital, Boston, Mass & Jonas $^{12}$ & Hemodilution and hypothermic cardiopulmonary bypass & 177 \\
\hline 1995 & Boston's Children Hospital, Boston, Mass & Wernovsky $^{13}$ & $\begin{array}{l}\text { Outcomes of the arterial switch operation for transposition } \\
\text { of the great arteries }\end{array}$ & 166 \\
\hline 2009 & Children's Hospital of Philadelphia, Philadelphia, Pa & Licht $^{14}$ & Brain maturation in patients with congenital heart defects & 118 \\
\hline 2002 & Children's Hospital of Philadelphia, Philadelphia, Pa & Gaynor $^{15}$ & Predictors of outcome following the Fontan procedure & 83 \\
\hline 2001 & Northwestern University, Chicago, Ill & Mavroudis $^{16}$ & Cavopulmonary conversion for Fontan operation failures & 82 \\
\hline
\end{tabular}

WoS, Web of Science citation index. 
TABLE 4. Top-ranking institutions

\begin{tabular}{lc}
\hline \multicolumn{1}{c}{ Institution } & $\begin{array}{c}\text { Number } \\
\text { of papers }\end{array}$ \\
\hline University of Toronto, Toronto, Canada & 12 \\
Cleveland Clinic, Cleveland, Ohio & 10 \\
Washington University, St Louis, Mo & 10 \\
Massachusetts General Hospital, Boston, Mass & 6 \\
University of Pittsburgh, Pittsburgh, Pa & 6 \\
Mayo Clinic, Rochester, Minn & 6 \\
University of Michigan, Ann Arbor, Mich & 5 \\
NewYork-Presbyterian Hospital (The University & 5 \\
$\quad$ Hospital of Columbia and Cornell), New York, NY & \\
Boston Children's Hospital, Boston, Mass & 5 \\
\hline
\end{tabular}

\section{CONCLUSIONS}

Over the past century, since the introduction of thoracic surgery, the field has flourished and diversified thanks to developments in surgical techniques, technologic advancements, and understanding of disease processes. Our intent in conducting this study was to highlight some of the most influential research presented at the AATS meeting and subsequently published in JTCVS during the past 20 years, in recognition of the approaching 100th anniversary of the Society. By looking back at the progress and contributions the AATS has made in the field of thoracic surgery, the authors hope that this review will stimulate further advances and serve as a guide for current and future surgical trainees.

\section{Conflict of Interest Statement}

Authors have nothing to disclose with regard to commercial support.

\section{References}

1. Meltzer SJ. First President's Address. The American Association for Thoracic Surgery Programme. Chicago, Ill: New York: New York Medical Record; June 10, 1918. 1919.

2. Lytle BW, Blackstone EH, Loop FD, Houghtaling PL, Arnold JH, Akhrass R, et al. Two internal thoracic artery grafts are better than one. J Thorac Cardiovasc Surg. 1999; 117:855-72.

3. Puskas JD, Williams WH, Duke PG, Staples JR, Glas KE, Marshall JJ, et al. Off-pump coronary artery bypass grafting provides complete revascularization with reduced myocardial injury, transfusion requirements and length of stay: a prospective randomized comparison of two hundred unselected patients undergoing off-pump versus conventional coronary artery bypass grafting. J Thorac Cardiovasc Surg. 2003;125:797-808.
4. Dake MD, Miller DC, Mitchell RS, Semba CP, Moore KA, Sakai T. The "first generation" of endovascular stent-grafts for patients with aneurysms of the descending thoracic aorta. J Thorac Cardiovasc Surg. 1998;116: 689-703.

5. Gillinov AM, Wierup PN, Blackstone EH, Bishay ES, Cosgrove DM, White J, et al. Is repair preferable to replacement for ischemic mitral regurgitation? J Thorac Cardiovasc Surg. 2001;122:1125-41.

6. Yacoub MH, Gehle P, Chandrasekaran V, Birks EJ, Child A, Radley-Smith R. Late results of a valve-preserving operation in patients with aneurysms of the ascending aorta and root. J Thorac Cardiovasc Surg. 1998;115:1080-90.

7. Pastorino U, Buyse M, Friedel G, Ginsberg RJ, Girard P, Goldstraw P, et al. Long-term results of lung metastasectomy: prognostic analyses based on 5206 cases. J Thorac Cardiovasc Surg. 1997;113:37-49.

8. Flores RM, Pass HI, Seshan VE, Dycoco J, Zakowski M, Carbone M, et al. Extrapleural pneumonectomy versus pleurectomy/decortication in the surgical management of malignant pleural mesothelioma: results in 663 patients. $J$ Thorac Cardiovasc Surg. 2008;135:620-6, 626.e1-3.

9. Grillo HC, Donahue DM, Mathisen DJ, Wain JC, Wright CD. Postintubation tracheal stenosis. Treatment and results. J Thorac Cardiovasc Surg. 1995;109: 486-92.

10. Boffa DJ, Allen MS, Grab JD, Gaissert HA, Harpole DH, Wright CD. Data from The Society of Thoracic Surgeons General Thoracic Surgery database: the surgical management of primary lung tumors. J Thorac Cardiovasc Surg. 2008; $135: 247-54$

11. Orringer MB, Marshall B, Iannettoni MD. Eliminating the cervical esophagogastric anastomotic leak with a side-to-side stapled anastomosis. $J$ Thorac Cardioavasc Surg. 2000;119:277-88.

12. Jonas RA, Wypij D, Roth SJ, Bellinger DC, Visconti KJ, du Plessis AJ, et al. The influence of hemodilution on outcome after hypothermic cardiopulmonary bypass: results of a randomized trial in infants. J Thorac Cardiovasc Surg. 2003; 126:1765-74.

13. Wernovsky G, Mayer JE, Jonas RA, Hanley FL, Blackstone EH, Kirklin JW, et al. Factors influencing early and late outcome of the arterial switch operation for transposition of the great arteries. J Thorac Cardiovasc Surg. 1995;109: 289-301.

14. Licht DJ, Shera DM, Clancy RR, Wernovsky G, Montenegro LM, Nicolson SC, et al. Brain maturation is delayed in infants with complex congenital heart defects. J Thorac Cardiovasc Surg. 2009;137:529-36.

15. Gaynor JW, Bridges ND, Cohen MI, Mahle WT, Decampli WM, Steven JM, et al. Predictors of outcome after the Fontan operation: Is hypoplastic left heart syndrome still a risk factor? J Thorac Cardiovasc Surg. 2002;123: 237-45.

16. Mavroudis C, Backer CL, Deal BJ, Johnsrude C, Strasburger J. Total cavopulmonary conversion and maze procedure for patients with failure of the Fontan operation. J Thorac Cardiovasc Surg. 2001;122:863-71.

17. O'Sullivan KE, Kelly JC, Hurley JP. The 100 most cited publications in cardiac surgery: bibliometric analysis. Ir J Med Sci. 2015;184:91-9.

18. Ahmad SS, Ahmad SS, Kohl S, Ahmad S, Ahmed AR. The hundred most cited articles in bariatric surgery. Obes Surg. 2015;25:900-9.

19. Kirklin JK, Naftel DC, Pagani FD, Kormos RL, Stevenson L, Miller M, et al. Long-term mechanical circulatory support (destination therapy): on track to compete with heart transplantation? J Thorac Cardiovasc Surg. 2012;144: 584-603.

Key Words: AATS, plenary sessions, citation

Readers who found these articles interesting may also like to read the following papers found in recent and future issues of our sister publications, Seminars in Thoracic and Cardiovascular Surgery and Operative Techniques in Thoracic and Cardiovascular Surgery!

Cardiothoracic Surgical Education and Training

News and Views: STS Adult Cardiac Surgery Database: The Driving Force for Improvement in Cardiac Surgery. AL Shroyer. Semin Thorac Cardiovasc Surg. 2015; Summer; 27(2):144-151. 